Hegemonia - Revista Eletrônica do Programa de Mestrado em Direitos Humanos, Cidadania e Violência/Ciência Política do Centro Universitário Unieuro

ISSN: $1809-1261$

UNIEURO, Brasília, número 23, Janeiro a Junho de 2018, pp. 178-210.

Recebido em: 24/9/2017

Avaliado em: 13/10/2017

Aprovado em: 10/11/2017

\title{
MÉXICO: la perspectiva de los estudiantes universitarios juarenses ante las reformas estructurales
}

Jesús Alberto Rodríguez Alonso, ${ }^{1}$ y Sergio Pacheco González ${ }^{2}$

RESUMEN: Considerando que hay un vacío en términos de estudios más profundos que tengan en cuenta las subjetividades sobre cuestiones importantes para el desarrollo del país, el objetivo de este trabajo es conocer los conocimientos, percepciones y valoraciones que los estudiantes universitarios de Ciudad Juárez tienen sobre las reformas estructurales que el gobierno ha desarrollado los últimos años. Para lograrlo se hizo través del análisis de diversas encuestas de opinión y cinco grupos focales que posibilitó una aproximación a las percepciones sobre la ciudadanía, democracia, política, y desempeño gubernamental.

PALABRAS CLAVES: Estudiantes universitarios, reformas estructurales, percepciones, Ciudad Juárez, democracia.

ABSTRACT: Considering that there is a gap in terms of deeper studies that take into account the subjectivities on issues important for the development of the country, the objective of this work is to know the perceptions, knowledge and evaluations that the university students of

${ }^{1}$ Doutor em Ciência Política e Administração e professor da Universidade Autônoma de Ciudad Juárez (México).

${ }^{2}$ Doutor em Ciências Sociais e professor da Universidade Autônoma de Ciudad Juárez (México). 
Artigo original

Hegemonia - Revista Eletrônica do Programa de Mestrado em Direitos Humanos, Cidadania e Violência/Ciência Política do Centro Universitário Unieuro

ISSN: $1809-1261$

UNIEURO, Brasília, número 23, Janeiro a Junho de 2018, pp. 178-210.

Ciudad Juarez have on the structural reforms that the government has developed in recent years. To achieve this was done through the analysis of various opinion polls and five focus groups that enabled an approach to perceptions about citizenship, democracy, politics, and government performance.

KEYWORDS: University students, structural reforms, perceptions, Ciudad Juarez, democracy.

RESUMO: Considerando que há um vazio em termos de estudos mais aprofundados que levem em conta as subjetividades sobre questões importantes para o desenvolvimento do país, o objetivo de este trabalho é apreciar os conhecimentos, percepções e valorações que estudantes universitários de Cidade Juarez têm sobre as reformas estruturares que o governo tem desenvolvido os últimos anos. Pra elo se fiz a traves de diversas pesquisas de opinião e cinco grupos focais uma aproximação ás percepções sobre a cidadania, democracia, política, e desempenho governamental.

PALAVRAS- CHAVE: Estudantes universitários, reformas estruturares, percepções, Cidade Juarez, democracia.

\section{Introducción}

En los últimos treinta y tres años (1982-2015), México ha pasado por un conjunto de reformas consideradas estructurales. Ciertamente estas reformas han tenido un conjunto de impactos, positivos algunos y otros negativos, mucha tinta se ha vertido al respecto desde las distintas disciplinas interesadas en éstas, desde la ciencia política, la sociología y la economía por mencionar algunas. De acuerdo con Trejo y Andrade (2013), las reformas implementadas en México pueden considerarse de tres generaciones, las de primera generación que buscaban principalmente estabilizar la economía del país y darle impulso hacia el crecimiento, éstas se dieron durante el periodo de 1984-1994; las de segunda generación, ubicadas entre 1996-2006 y que tuvieron como objetivo, además de profundizar en los cambios ya iniciados en la primera 
Artigo original

Hegemonia - Revista Eletrônica do Programa de Mestrado em Direitos Humanos, Cidadania e Violência/Ciência Política do Centro Universitário Unieuro

ISSN: $1809-1261$

UNIEURO, Brasília, número 23, Janeiro a Junho de 2018, pp. 178-210.

generación, acrecentar la apertura comercial y aumentar la integración de la economía mexicana al proceso de globalización. Finalmente, las de tercera generación son las que ya se están aprobando desde el regreso del Partido Revolucionario Institucional (PRI) a Los Pinos; estas reformas son una continuidad de lo iniciado en los ochenta, es decir una mayor integración al proceso globalizador, mayor participación de la iniciativa privada, nacional y extranjera, y más reducción del papel del Estado. Estas reformas han tenido algunos éxitos macroeconómicos pero una cantidad mucho mayor de limitaciones, tanto en lo microeconómico como en lo social y lo político.

Si bien existen encuestas específicas relativas a las reformas estructurales, como la Encuesta Nacional Sobre las Reformas Estructurales, efectuada por la LXII Legislatura de la Cámara de Diputados en agosto del 2014, a través del Centro de Estudios Sociales y de Opinión Pública (CESOP), ${ }^{3}$ consideramos que hay un vacío en cuanto a estudios más profundos que den cuenta de las subjetividades de las personas en relación a temas importantes para el desarrollo del país. Es decir se requiere se acercamientos cualitativos focalizados en determinados grupos etarios o sociales.

Tomando en consideración lo anterior, se hace pertinente cuestionarnos cuáles son los conocimientos, percepciones y valoraciones que se tienen sobre las reformas estructurales implementadas por el actual gobierno. Por ello, el objetivo de este trabajo es describir las perspectivas, en sentido de conocimientos, percepciones y valoraciones, que poseen los estudiantes universitarios de Juárez respecto a las reformas estructurales.

Las ideas que guían estas reflexiones se orientan en la cultura política específicamente a tres grandes temas: la política, la ciudadanía, la democracia y el desempeño gubernamental. Es decir, las respuestas existentes en relación a la percepción y sentimientos sobre la política; qué

\footnotetext{
3 Dicha encuesta se realizó en viviendas de 190 localidades del país, centrada en cinco reformas específicas: energética, educativa, laboral, hacendaria y de telecomunicaciones (CESOP 2014), y en la que se hacen acercamientos cuantitativos y generales a la población mayor de 18 años.
} 
Artigo original

Hegemonia - Revista Eletrônica do Programa de Mestrado em Direitos Humanos, Cidadania e Violência/Ciência Política do Centro Universitário Unieuro

ISSN: $1809-1261$

UNIEURO, Brasília, número 23, Janeiro a Junho de 2018, pp. 178-210.

tan democrático se considera que es el país, y cuál su perspectiva sobre la ciudadanía y su autopercepción ante ello.

Para realizar esta exploración se realizaron cinco grupos focales, cuatro mixtos y uno de hombres, con estudiantes universitarios, hombres y mujeres entre los 18 y 28 años de edad, que cursan programas de pregrado en diferentes carreras e institutos de la Universidad Autónoma de Ciudad Juárez (UACJ). Se optó por realizar grupos focales considerando, de acuerdo con Morgan (1996) y Morgan y Spanish (1984), que constituyen una herramienta adecuada para estudios cualitativos de actitudes y opiniones, que a diferencia de las técnicas cuantitativas, precisa Martínez (2004), "la muestra de estudio no responde a criterios estadísticos, sino estructurales, es decir, a su representatividad de determinadas relaciones sociales en la vida real."

El documento se estructura en tres secciones, la primera que se ocupa de realizar un acercamiento conceptual y a las percepciones, conocimientos y valoraciones hacia la democracia en el país, la política, la ciudadanía y el desempeño gubernamental. Igualmente efectuamos un breve acercamiento a las reformas estructurales y los resultados de la opinión rescatada en la encuesta del (CESOP, 2014).

En la segunda sección se expondrán los resultados obtenidos en los cinco grupos focales efectuados con estudiantes universitarios, es decir detallaremos las percepciones y perspectivas de estudiantes universitarios ante las reformas estructurales. Finalmente en la tercera sección se presentarán algunas reflexiones respecto a los hallazgos, las interrogantes y retos que hayan observado a partir de este trabajo.

\footnotetext{
${ }^{4}$ Los autores agradecen a las estudiantes del Programa de Sociología de la UACJ, Elisa Lucero Peña y Cecilia Martínez Lozano, por la coordinación y transcripción de los grupos focales.
} 
Artigo original

Hegemonia - Revista Eletrônica do Programa de Mestrado em Direitos Humanos, Cidadania e Violência/Ciência Política do Centro Universitário Unieuro

ISSN: $1809-1261$

UNIEURO, Brasília, número 23, Janeiro a Junho de 2018, pp. 178-210.

2. La cultura política en México

2.1 La política y la democracia

En este apartado describimos cómo es concebida la política y la democracia en México, para ello hacemos uso de diversos documentos, como el Informe País sobre la Calidad de la Ciudadanía en México (IPCCM 2014); Quinta Encuesta Nacional de Cultura Política y Prácticas Ciudadanas (ENCUP 2012) y la Encuesta sobre Ciudadanía y Participación (ECP 2014), elaborado por el El Colegio Mexiquense en diciembre 2014.

Uno de los primeros elementos que rescatamos es respecto a la percepción de lo complicada que es la política; ante la pregunta de la (ENCUP 2012), de qué tan complicada es la política, el 48.5 por ciento considera a la política muy complicada, seguida por 35.8 que menciona que es poco complicada, tabla 1. Ello nos evidencia un alto nivel de desconocimiento ante el funcionamiento o comprensión de la política.

\begin{tabular}{|l|l|}
\hline \multicolumn{2}{|l|}{ Tabla 1. Visión sobre lo complicado de la política } \\
\hline Nivel de complicación & Porcentaje \\
\hline Muy complicada & 48.5 \\
\hline Poco complicada & 35.8 \\
\hline Nada complicada & 14.2 \\
\hline Otra & .7 \\
\hline No sé & .7 \\
\hline No contesta & .1 \\
\hline
\end{tabular}

Fuente. Elaboración propia con datos de la ENCUP 2012.

Sin embargo al ser cuestionados respecto a la mejor forma de resolver los problemas de la sociedad, a preguntas expresas respondieron lo siguiente: 77.8 por ciento considera que éstos 


\section{Artigo original}

Hegemonia - Revista Eletrônica do Programa de Mestrado em Direitos Humanos, Cidadania e Violência/Ciência Política do Centro Universitário Unieuro

ISSN: 1809-1261

UNIEURO, Brasília, número 23, Janeiro a Junho de 2018, pp. 178-210.

deben resolverse con la participación del gobierno y la sociedad; 50.7 por cierto mencionó que lo debe hacer el gobierno y únicamente 34.3 por ciento que lo debe hacer la sociedad (ENCUP 2012). Este aspecto resalta una forma de cultura política que describió en su momento Almond y Verba (1968) como una cultura predominantemente subordinada, ya que al contrastarlo con la idea de qué tanto creen que los ciudadanos influyen en la vida política del país, el 52.8 por cierto considera que poco o nada y el 48.3 por cierto considera la influencia de las agrupaciones ciudadana de poco o nada. Lo anterior ya fue señalado por el (IPCCM 2014:85). Aún no existe una cultura de participación en la comunidad que permita el cambio en la sociedad por parte de sus propios miembros.

La democracia como forma de gobierno, sólo el 33 por cierto percibe que en México se viva en democracia, el 33.6 mencionó que sí pero parcialmente, y el 31 por ciento que no. De aquellos que mencionaron que viven en democracia, el 30 por cierto mencionó estar satisfecho o muy satisfecho. Un 53 por cierto poco o nada satisfecho y un 17 por cierto le da igual, es decir ni satisfecho ni insatisfecho con la democracia (ENCUP 2012). Lo anterior se refuerza con la respuesta que dan respecto a la expectativa que se tenía del país en el 2000 y la realidad que se vive en el 2014. Respecto a la pregunta de qué tanto se parece el México actual al que usted esperaba en el año 2000, sólo el 10.7 por ciento lo considera mejor; únicamente el 16.1 por ciento dice que es igual a como lo imaginó y 69.3 por ciento menciona que es peor o mucho peor de lo que se imaginó (tabla 2). Ciertamente en esta respuesta se rescata el imaginario, el cual se ve influido por una multiplicidad de variables que van desde lo económico y político pasando por aspectos personales, sin embargo resalta un elemento de contraste negativo entre lo imaginado y la realidad, ello aumenta el nivel de angustia, desinterés y desencanto, tanto en el fuero interno como en el entramado externo que tiene que ver con las instituciones y su comunidad. (Castoriadis 1997). 


\section{Artigo original}

Hegemonia - Revista Eletrônica do Programa de Mestrado em Direitos Humanos, Cidadania e Violência/Ciência Política do Centro Universitário Unieuro

ISSN: $1809-1261$

UNIEURO, Brasília, número 23, Janeiro a Junho de 2018, pp. 178-210.

\begin{tabular}{|l|l|}
\hline \multicolumn{2}{|l|}{ Tabla 2. Parecido del México actual al del 2000} \\
\hline Comparación & Porcentaje \\
\hline Es mucho mejor que como imaginé & 2.1 \\
\hline Es mejor que lo que imaginé & 8.6 \\
\hline Es como lo imaginé & 16.2 \\
\hline Es peor que lo que imaginé & 47.7 \\
\hline Es mucho peor que lo que imaginé & 21.6 \\
\hline NS/NC & 3.8 \\
\hline
\end{tabular}

Fuente. Elaboración propia con datos de la ECP 2014.

Asimismo, la Encuesta Nacional sobre Reformas Estructurales, destaca que, ante la pregunta, ¿Qué palabra describe mejor cómo se siente usted sobre la situación actual del país?, el 76 por ciento mencionó sentimientos negativos que van desde malestar/molestia 19 por ciento, tristeza/pesimismo 11 por ciento, coraje/enojo/ira 10 por ciento, miedo/preocupación/intranquilidad 10 por ciento, desilusión/decepción 7 por ciento, entre otras (ECP 2014).

Los datos anteriores en cierta medida confirman lo expuesto hasta aquí: los mexicanos en su mayoría se sienten decepcionados por las condiciones económicas, políticas y sociales del país, ello conlleva que se sientan menos impulsados a participar y a acercarse a la política como un asunto relevante en sus vidas, aún y cuando un 49 por ciento considera que el principal problema del país es el económico, seguido con un 32 por ciento del de inseguridad (ECP 2014). Consideramos que el problema es en realidad más de orden político, tal como lo afirman Rubio, Azuara, Jaime y Hernández (2006, 6-7): "El verdadero reto no es de naturaleza económica, ya que existen soluciones técnicas que han sido probadas en otras naciones. Nuestro desafío es organizarnos de una manera adecuada para poder adoptar las medidas de carácter técnico necesarias. Y éste es un problema político". 


\section{Artigo original}

Hegemonia - Revista Eletrônica do Programa de Mestrado em Direitos Humanos, Cidadania e Violência/Ciência Política do Centro Universitário Unieuro

ISSN: $1809-1261$

UNIEURO, Brasília, número 23, Janeiro a Junho de 2018, pp. 178-210.

\subsection{La ciudadanía y las reformas estructurales}

De acuerdo al Informe País la democracia incluye ideas respecto de que es el gobierno de todos los ciudadanos que expresan su voluntad popular principalmente -aunque no solamente- a través de la elección de los gobernantes. (IPCCM 2014, 120). En este sentido y afianzando la idea que prevalece en los mexicanos, en la democracia muchos participan y pocos ganan (50 por ciento); contra el 26 por ciento de que las reglas son para todos. Estos porcentajes corresponden a la pregunta de si creían que en la democracia todos colaboran para logran el mismo objetivo, si en ella las reglas son iguales para todos, o si en ella participan muchos y ganan pocos. En este mismo sentido, las personas al ser cuestionadas respecto a las reformas estructurales y el beneficio que obtendría, obtuvimos los resultados que se describen a continuación en la tabla 3.

\begin{tabular}{|l|l|l|l|l|l|l|}
\hline & \multicolumn{1}{|l|}{$\begin{array}{l}\text { Tabla 3. Beneficiados por las reformas estructurales, } \\
\text { porcentajes de respuesta }\end{array}$} \\
\hline Beneficiado & $\begin{array}{l}\text { Energé- } \\
\text { tica }\end{array}$ & $\begin{array}{l}\text { Telecomuni- } \\
\text { caciones }\end{array}$ & $\begin{array}{l}\text { Educa- } \\
\text { tiva }\end{array}$ & $\begin{array}{l}\text { Labo- } \\
\text { ral }\end{array}$ & $\begin{array}{l}\text { Hacen } \\
\text {-daria }\end{array}$ & Promedio \\
\hline $\begin{array}{l}\text { Al gobierno del } \\
\text { Presidente Peña Nieto }\end{array}$ & 77 & 73 & 72 & 68 & 77 & 73.4 \\
\hline $\begin{array}{l}\text { A la población en } \\
\text { general }\end{array}$ & 38 & 70 & 75 & 58 & 22 & 52.6 \\
\hline A usted y su familia & 37 & 68 & 76 & 55 & 20 & 51.2 \\
\hline
\end{tabular}

Fuente. Elaboración propia con datos de CESOP, 2014

Queda claro que la visión existente, respecto a quién es el que resulta más beneficiado por las reformas estructurales, es el gobierno del Presidente Peña Nieto, salvo en la reforma educativa, 


\section{Artigo original}

Hegemonia - Revista Eletrônica do Programa de Mestrado em Direitos Humanos, Cidadania e Violência/Ciência Política do Centro Universitário Unieuro

ISSN: $1809-1261$

UNIEURO, Brasília, número 23, Janeiro a Junho de 2018, pp. 178-210.

que opinaron que los más beneficiados es el propio respondiente y su familia. Si cruzamos esta respuesta con la relativa a ¿Qué tanto cree que les interesa lo que piensa la gente como usted al gobierno federal? El 53.4 por ciento mencionó que nada y el 34.8 por ciento poco; igual el 73.8 por ciento menciona que cree que a los funcionarios públicos no les preocupa lo que piensa la gente como ella. (ENCUP 2012).

Podemos afirmar que la percepción ciudadana respecto a las reformas estructurales es reducida, ya que se tiene un bajo conocimiento de las mismas, en la Encuesta sobre Reformas Electorales (CESOP 2014, 39-40) se describe que el 35 por ciento de los encuestados no recordaba o no sabía sobre ninguna; las más recordadas fueron la energética con un 41 por ciento y la educativa con 38 por ciento; la reforma político electoral sólo la recordó el tres por ciento. En este sentido no se puede pensar en una ciudadanía integral o sustantiva, es decir acceso pleno a los derechos civiles, políticos y sociales (Olvera 2008, 47) sino más bien una ciudadanía débil o precaria.

Respecto a la valoración del desempeño gubernamental, el 64.4 por ciento considera que no es el adecuado y el 55.4 por ciento ve la situación económica como mala o muy mala; en este sentido observamos que la valoración económica y del desempeño de gobierno es baja, por lo que podemos afirmar que nos encontramos en una zona de malestar con la política.

El concepto de malestar con la política está ligado a las percepciones de los ciudadanos y no a condiciones objetivas de la economía ni de las instituciones políticas... Asimismo el malestar con la política no es equiparable con una "mala calidad" de la democracia o con un diseño institucional subóptimo...La ciudadanía puede sentirse insatisfecha bajo contextos institucionales óptimos si sus expectativas en relación al desempeño de esas instituciones no se ven colmada... y por último, la satisfacción de los ciudadanos en relación con la política y su desempeño tiene una relación directa con sus expectativas (Moreno y Araníbar 2012, 189-90). 
Artigo original

Hegemonia - Revista Eletrônica do Programa de Mestrado em Direitos Humanos, Cidadania e Violência/Ciência Política do Centro Universitário Unieuro

ISSN: $1809-1261$

UNIEURO, Brasília, número 23, Janeiro a Junho de 2018, pp. 178-210.

3. Percepciones y perspectivas de estudiantes universitarios ante las reformas estructurales

Como indica Norbert Elias (1999), las relaciones entre las personas constituyen un tejido de acciones interdependientes, definidas a partir de las posiciones que ocupan y de las expectativas que poseen de la mutua satisfacción de necesidades, entre ellas y de manera primordial las de carácter emocional. En este sentido, cuando nos interrogamos sobre las percepciones y perspectivas que tiene la ciudadanía sobre las llamadas reformas estructurales, resulta necesario identificar cuál es la posición, es decir desde dónde elaboran el discurso las personas que son consultadas. En este caso, como parecen sugerir los resultados de esta exploración, el ser estudiante y ubicarse como tal, dota de particular sentido tanto a percepciones como a perspectivas.

\subsection{Percepciones}

Las percepciones, como indica Luz María Vargas Melgarejo (1994:48) representan más que "un proceso lineal de estímulo y respuesta sobre un sujeto pasivo,..., están de por medio una serie de procesos en constante interacción y donde el individuo y la sociedad tienen un papel activo". En este sentido, precisa: "La cultura de pertenencia, el grupo en el que se está inserto en la sociedad, la clase social a la que se pertenece, influyen sobre las formas como es concebida la realidad, las cuales son aprendidas y reproducidas por los sujetos sociales." (49) Si bien podemos considerar que la ubicación en un grupo social específico, influye en las percepciones y representaciones que elaboran sus miembros, consideramos que de su aprendizaje y análisis no se deriva necesariamente su reproducción, como se podrá apreciar en el apartado reservado a comunicar las perspectivas que sobre las reformas estructurales tienen las y los estudiantes consultados. En esta sección mostramos las opiniones que las personas 
Artigo original

Hegemonia - Revista Eletrônica do Programa de Mestrado em Direitos Humanos, Cidadania e Violência/Ciência Política do Centro Universitário Unieuro

ISSN: $1809-1261$

UNIEURO, Brasília, número 23, Janeiro a Junho de 2018, pp. 178-210.

manifiestan a partir de la mayor o menor información que poseen al momento de la interacción.

Los grupos focales indagaron sobre las nociones de ciudadanía, política, democracia y reformas estructurales, tratando de conocer qué efectos observan prevén tendrán éstas en lo personal, en lo social y cuáles son prioritarias. Así, en este apartado hacemos referencia a las tres primeras nociones, reservando lo relativo a las reformas para el siguiente.

\subsubsection{Ciudadanía}

Teóricamente, el concepto de ciudadanía ha sido motivo de muchas discusiones y diversas elaboraciones, así encontramos ciudadanía social, política, formal, sustantiva, popular, juvenil, entre otras. No es objetivo de este trabajo abundar en la discusión y sus múltiples elaboraciones, sino atender a las que las personas declaran, quizá, como indican Loreto Martínez y otras (2010:25) para el caso chileno: "Los jóvenes adscriben a una ciudadanía activa que valora la responsabilidad de informarse y la deliberación de los ciudadanos. A la base de sus creencias y aspiraciones de ciudadanía emergen los valores de fraternidad, dignidad y equidad."

En el discurso se observa un amplio abanico de respuestas que recogen, por una parte la definición normativa vinculada al ejercicio de derechos y responsabilidades, como acercamientos al origen o fuente de la ciudadanía, del estatus de ciudadano y de su ejercicio. Por ejemplo, para Félix ser ciudadano significa, como persona, "ser un sujeto de obligaciones y de derechos. Ahora sí pasamos a un contexto político, un contexto de sociedad, nos convertimos en ciudadanos, tanto nuestros derechos como nuestras obligaciones son puramente, no políticos, sino sociales.

Como él, Jessica identifica derechos y responsabilidades, además de delimitar un espacio para el ciudadano: "que vive en un lugar, que forma parte de un país", como lo hace Paola: "es una persona que vive en un lugar, que sea una ciudad" o bien que nace en ella, pues "de hecho, 


\section{Artigo original}

Hegemonia - Revista Eletrônica do Programa de Mestrado em Direitos Humanos, Cidadania e Violência/Ciência Política do Centro Universitário Unieuro

ISSN: 1809-1261

UNIEURO, Brasília, número 23, Janeiro a Junho de 2018, pp. 178-210.

desde el momento en el que naces ya te puedes considerar un ciudadano", lo que comparte Alán: "eres ciudadano desde el momento en el que naces, aunque aún tus derechos no estén del todo claro, ni tus atribuciones tampoco." Victoria lo acerca a la noción de identidad: "Creo que un ciudadano es toda aquella persona que nace en una ciudad y que tiene sus derechos y obligaciones con esa misma ciudad donde vive," lo que Arturo hace evidente: "es una identidad, es un ser parte de algo y sentirte con personas que son semejantes a ti y tienen, no sé, las mismas obligaciones.” Identificarse y ser identificado son elementos que Edgar toma en cuenta: "un ciudadano es parte de una sociedad, de una ciudadanía específicamente identificado con un lugar y que cuenta con sus derechos y está obligado a retribuir a la sociedad que lo identifica como uno mismo."

Esta concepción es replanteada por Natalia, quien no toma como base la delimitación política administrativa, sino al actor social: "Para mí era como que muy chiquito el conceptito, todos lo conformamos si no, no existiría la ciudad, así que un ciudadano es quien participa para que exista la ciudad." Juicio que comparten Diego: "El ciudadano mexicano tiene una gran importancia dentro de la sociedad, porque es, como algunos teóricos que dicen que la familia es la célula básica de toda la sociedad, el ciudadano es la célula, es la unidad esencial y básica de toda la sociedad", y Jorge: "un ciudadano viene a ser la unidad fundamental de una sociedad, de ahí partimos como sociedad hacia el Estado, tiene obligaciones tiene derechos, tiene que estar pendiente además de sus obligaciones propias... y también las que competa[n] al Estado.”

Iskra sitúa derechos y obligaciones "dentro del marco de la legalidad", establece un criterio etario: "de 18 años o más”, relativiza el origen o lugar de residencia, y destaca la participación activa "dentro de la sociedad, dentro de la economía, de la política, de sus prácticas culturales". Ethiel comparte esta concepción y reinserta el ámbito político administrativo: "Un ciudadano es parte de un Estado antes que nada, y debe de sentirse identificado con los aspectos que cubren el estado y debe de ser el país, debe de ser la nación y debe de ser, por parte de la legalidad." 


\section{Artigo original}

Hegemonia - Revista Eletrônica do Programa de Mestrado em Direitos Humanos, Cidadania e Violência/Ciência Política do Centro Universitário Unieuro

ISSN: 1809-1261

UNIEURO, Brasília, número 23, Janeiro a Junho de 2018, pp. 178-210.

En el mismo sentido se expresa Alejandro, quien considera que un ciudadano se caracteriza por "ser partícipe proactivo dentro de la sociedad, como individuos, como personas, como familia, y siempre estar atento a los cambios que ocurren dentro de la sociedad”. Diego, "abona" a lo expresado: "es una persona que habita un espacio, rodeado de personas, que es una sociedad, pero más que eso es una persona comprometida con esa sociedad y que además de estar comprometida sabe sus derechos, sabe sus obligaciones.” El ciudadano, poseedor de derechos y obligaciones, se caracteriza así, por estar informado y participar, desde sus diferentes posiciones sociales, en aquello que le atañe como integrante de la sociedad. Se distingue, indica Diego, del simpe estatus de habitante, en tanto “está interesado, está al pendiente y está comprometido con asuntos públicos de su mismo grupo social”. Como indica Alan: "Para mí el termino ciudadano es todavía más amplio, parte de las obligaciones y derechos que tienes en la participación no nomás política sino de la convivencia social”.

Otras concepciones son críticas del ámbito normativo y de los límites de la participación. Por ejemplo, Alondra cuestiona: “para mí el ciudadano es parte del sistema que nos rige ¿no?” Ante ello, Julián establece una analogía con el conflicto entre Estados:

Yo pienso que un ciudadano es un prisionero casi como de guerra, al cual se le niega toda su libertad y siempre se le está acosando y vigilando, es un individuo, ya no individuo si no un ente que está siempre sometido por algo mucho más grande que todo lo gobierna y todo lo domina.

Alfredo vincula ambos juicios y establece su coincidencia:

Yo también pienso lo mismo que Julián que también son prisioneros, somos sometidos por un sistema para que formemos también parte de él, entonces siempre estamos trabajando para algo que nos está regulando, yo creo que nosotros como ciudadanos tenemos ciertas normativas de nosotros mismos que queremos cumplir pero este mismo sistema no nos deja cumplir con lo que nosotros queremos y nos pone ideales como el patriotismo, así que yo también pienso que somos prisioneros políticos. 
Artigo original

Hegemonia - Revista Eletrônica do Programa de Mestrado em Direitos Humanos, Cidadania e Violência/Ciência Política do Centro Universitário Unieuro

ISSN: $1809-1261$

UNIEURO, Brasília, número 23, Janeiro a Junho de 2018, pp. 178-210.

Jesús coincide en la necesidad de "crear conciencia crítica por supuesto, se tiene que ver desde un punto de vista analítico pero no se tiene que enajenar. Comparto el pensamiento que hasta cierto punto somos controlados y un punto importante en esto es la manipulación mediática". Y sentencia: "Es la ciudadanía lo que realmente hace una ciudad". Algo que para Alan:

Suena muy idealista y muy romántico que la ciudadanía sea el responsable de ver por su bien, pero lo que muchas veces en Estados como el mexicano es que tenemos una ciudadanía que exige derechos de primer mundo cuando ellos mismos son una ciudadanía de quinta clase, ese es un problema muy grave, ósea la ciudadanía debería tener mucha responsabilidad sobre sí misma,... no puedes elegir un mejor gobierno cuando ellos mismos no hacen lo suficiente como ciudadanía.

Se establece así una vieja discusión: ¿la ciudadanía está madura para gobernarse a sí misma? Según Alfredo no:

...no pienso yo que la ciudadanía tenga esa madurez social como para gobernarse ellos mismos, por eso mismo tienen esa inseguridad, entonces hasta que dejen de lado esas inseguridades van a dejar de lado ese idealismo, porque hay personas que todavía no están preparadas para ellas mismas gobernar su vida.

Alejandro podría no estar de acuerdo, para él existe falta de reconocimiento de las aportaciones de las y los jóvenes, en la medida que la "sociedad" los considera "inmaduros, por tener ideas totalmente locas.... Afecta[ndo] directamente nuestros derechos de la libre expresión, algo que sin duda es lo que más nos hace ser ciudadanos y aportar lo más importante para la sociedad: nuestro punto de vista." Para Jacobo no es así necesariamente, pues no todas las personas se comprometen ni ejercen sus derechos: "digo nos, porque soy parte de eso, pero pues no comprometidos con los roles que realmente nos tocan." 
Artigo original

Hegemonia - Revista Eletrônica do Programa de Mestrado em Direitos Humanos, Cidadania e Violência/Ciência Política do Centro Universitário Unieuro

ISSN: $1809-1261$

UNIEURO, Brasília, número 23, Janeiro a Junho de 2018, pp. 178-210.

\subsubsection{Política}

Como se pudo observar, la ciudadanía se relaciona con el ámbito de lo político y de la política, si bien predomina la concepción de que aquella es la expresión de lo que los sujetos realizan para y dentro de su ciudad, comunidad o Estado.

Cuando se les solicitó a las personas consultadas que mencionaran con cuáles palabras relacionan la palabra política, se mencionaron mayoritariamente, como expresa Diego: "puros calificativos que realmente son negativos e interminables", véase la imagen número 1. Para algunos, como Diego, la política se identifica con los políticos, los partidos y “el sistema”, el que decía Alondra, rige al ciudadano:

Pues porque dependen de otras personas, porque tienen favoritismo y tienen que responder con dinero, porque el mismo partido político los obliga a que se desempeñen en ese lineamiento, puede ser que el sistema está hecho para que la corrupción sea una forma ineludible para todos los funcionarios públicos, entonces, aún sin generalizar y decir que todos los políticos son malos, hay políticos que tienen excelentes intenciones y que son bien habidos, que son una minoría, y que en algún momento de sus funciones o de la ejecución de los mismos tienen que inmiscuirse en actos de corrupción.

El término corrupción fue el más mencionado de él se derivaron comportamientos varios, oportunismo, enriquecimiento ilícito, nepotismo o robo. Estas prácticas son contempladas como guía de acción para algunos, indica Jacobo:

Tengo compañeros que estudian en otras escuelas,..., que están estudiando derecho... o algo así me parece, y un día otro compañero me dice: "Nosotros vamos a llegar hasta el Senado, cueste lo que cueste, pero vamos a llegar, para robar, para hacernos millonarios, para sacar el dinero, dinero, dinero”. 


\section{Artigo original}

Hegemonia - Revista Eletrônica do Programa de Mestrado em Direitos Humanos, Cidadania e Violência/Ciência Política do Centro Universitário Unieuro

ISSN: $1809-1261$

UNIEURO, Brasília, número 23, Janeiro a Junho de 2018, pp. 178-210.

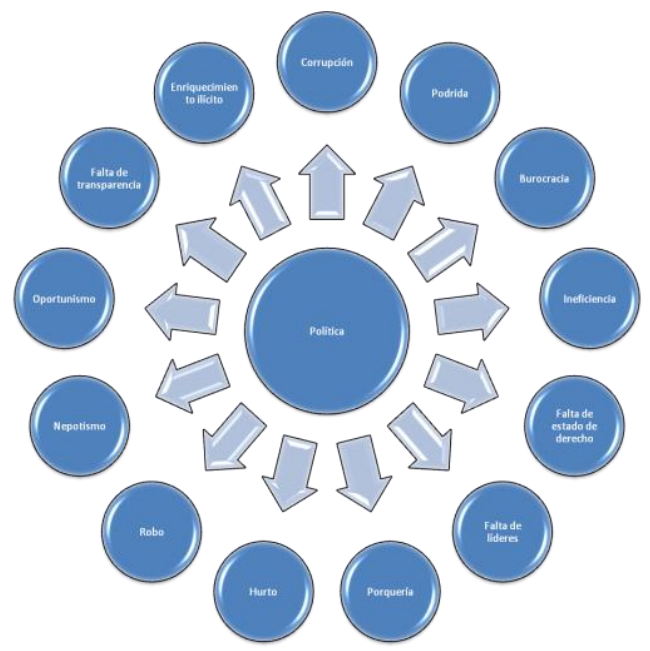

Imagen 1. Términos asociados negativamente con el concepto de política.

Aspectos no necesariamente negativos se asociaron a fundamentalmente con la organización, la estructura y las instituciones, vinculadas con el gobierno y los partidos políticos (Imagen 2). Se destacan aquellos que se refirieron a cambio, oportunidad y reformas, así como a las relaciones y el poder. Con relación a este último se menciona la falta de líderes, lo que haría deficiente al sistema y limitaría las posibilidades de transformación. Al respecto, comenta Gregorio: 


\section{Artigo original}

Hegemonia - Revista Eletrônica do Programa de Mestrado em Direitos Humanos, Cidadania e Violência/Ciência Política do Centro Universitário Unieuro

ISSN: 1809-1261

UNIEURO, Brasília, número 23, Janeiro a Junho de 2018, pp. 178-210.

...alguien decía "La política es tan importante que no se le puede dejar a los políticos" y yo veo una situación de mucha pasividad en la sociedad, no están conscientes del

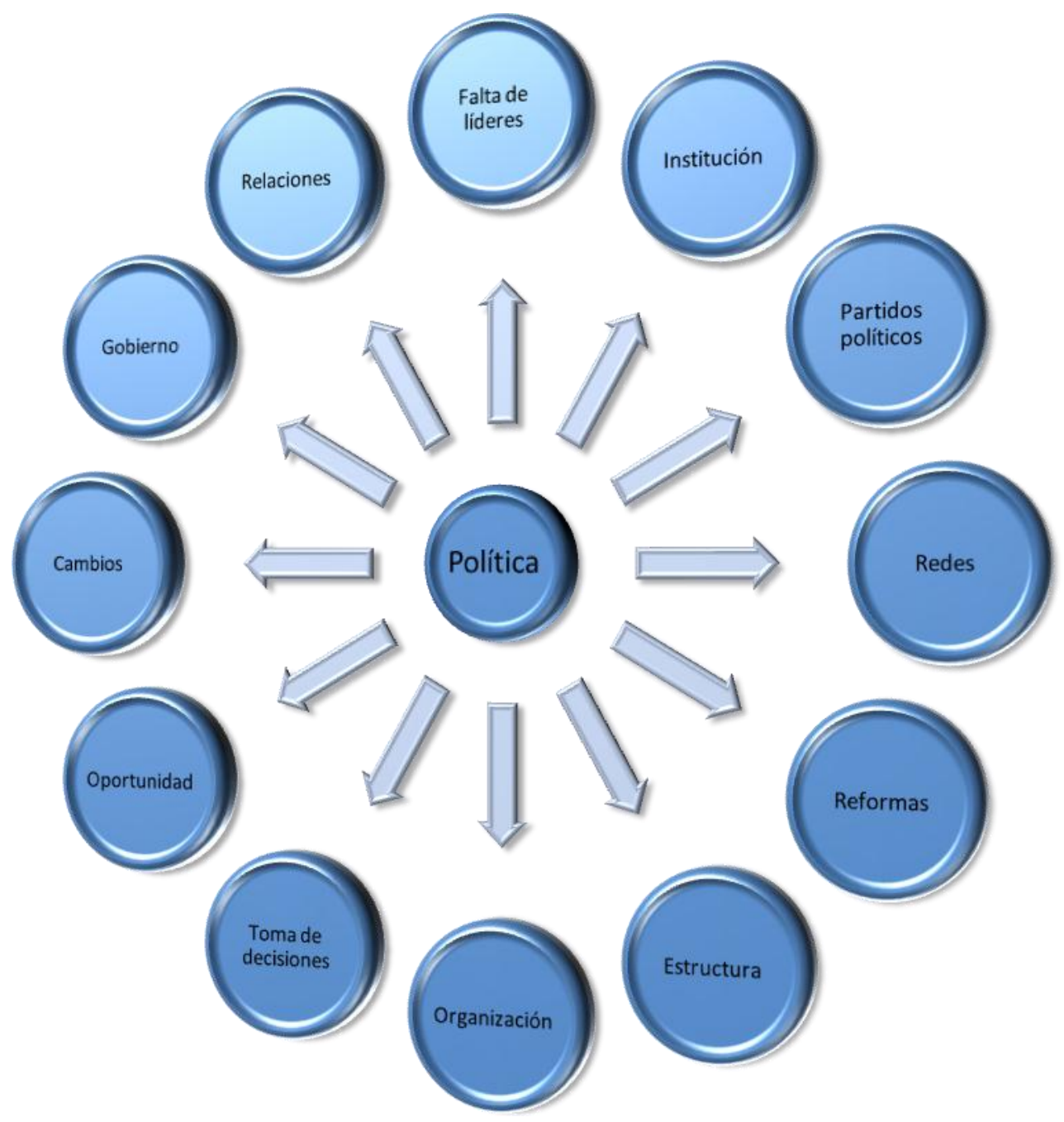

Imagen 2. Términos positivos asociados al concepto de política. 
Artigo original

Hegemonia - Revista Eletrônica do Programa de Mestrado em Direitos Humanos, Cidadania e Violência/Ciência Política do Centro Universitário Unieuro

ISSN: $1809-1261$

UNIEURO, Brasília, número 23, Janeiro a Junho de 2018, pp. 178-210.

potencial que ellos pueden ejercer a través de la política, a través de las instituciones.

Para algunos existe desinterés sobre la política y éste se debe entre otras razones, como indica Aldo, a que existen diversas barreras:

...son el Estado, y la cultura, la ciudadanía en realidad no tiene una educación cívica, o sea no entiende lo que es ser ciudadano, por ejemplo, nosotros estamos estudiando y no tengo claro el concepto de ciudadanía, pero considero que la población en general no conoce el concepto de ciudadanía, no conoce los derechos y las obligaciones que tiene como ciudadano y creo que ahí está el problema y el por qué esta ese desinterés hacia las cuestiones políticas.

Se podría resumir la cuestión como lo hace Ángel:

La política, la veo como lo que debería de ser y lo que es, lo que debería de ser trata de cómo gobernar y como dirigir el bien común, pero nos damos cuenta que eso no es lo que sucede, hay un conflicto de intereses y eso nos lleva a la corrupción, que no se cumpla el estado de derecho como decían mis compañeros.

\subsubsection{Democracia}

Para abordar su concepción de democracia, se les solicitó expresarán que sienten cuando escuchan esta palabra. Al respecto se manifestaron posturas encontradas. Para algunas personas, se encuentra relacionada con la participación ciudadana, los partidos políticos y las elecciones:

De que se lleva democráticamente se lleva, existe una legislación, existen organismos que se encargan de velar porque el proceso se lleve de manera democráticamente efectivamente, porque de que toda persona tiene derecho al voto, lo tiene... la gente se 


\section{Artigo original}

Hegemonia - Revista Eletrônica do Programa de Mestrado em Direitos Humanos, Cidadania e Violência/Ciência Política do Centro Universitário Unieuro

ISSN: 1809-1261

UNIEURO, Brasília, número 23, Janeiro a Junho de 2018, pp. 178-210.

ha visto desmotivada y ya no tiene un incentivo pata realizar el proceso y llevarlo a cabo; pero, de que existe como tal, sí existe, desde mi punto de vista. (Jorge)

Para otras, algo que no existe en la realidad, como indica Arturo: "la democracia, yo tengo entendido que busca el bien común, pero pues yo si veo el problema..., la democracia es el bien para todos, pero pues, es algo como muy iluso, algo que realmente no creo que exista.” Al respecto dice Aldo: "Puede haber democracia en cada uno de los diferentes países, y las comparas con México y dices tú -'Ah canijo, yo esa democracia no la conozco"'.

Entre el idealismo y el descrédito, la lucha de poder y la corrupción se presentan:

Sí la vemos en un sentido de idealismo, debería ser el gobierno perfecto, debería ser el gobierno que el mismo pueblo pone para representarlo de acuerdo a los intereses del pueblo y de acuerdo a lo que necesita el pueblo.... en este momento es todo menos eso, es incluso llegada a nombrarse como "aristocracia" porque en sí no es el gobierno del pueblo, es el gobierno de poca gente de muchos recursos, de mucho dinero, de mucho poder... y a ellos lo único que les interesa es seguirse enriqueciendo y seguir teniendo más poder y más poder y más poder. (Edgar)

La democracia parece haber sido delimitada al sistema de partidos, pues, como reflexiona David:

...si se lleva una cierta democracia pero no en todo su esplendor, porque en el país existen 10 partidos políticos los cuales, ellos mismos eligen a sus prospectos que esos, no son elegidos por la sociedad, y eso ya delimita en sí a la elección de los ciudadanos...¿para qué votar? Si estos ya eligieron a sus gobernantes, por ello, esa es la principal razón por la que creo que no existe una buena democracia aquí en México.

En el mismo sentido se expresa Jesús:

Ciertamente es un concepto muy romántico, el poder del pueblo ¿no?, y ciertamente ¿cuándo ha tenido el poder el pueblo?, hay que hacerse esa pregunta, es muy romántica la democracia, "el poder del pueblo", pero vivimos en una sociedad muy compleja donde todo ya está establecido. 
Artigo original

Hegemonia - Revista Eletrônica do Programa de Mestrado em Direitos Humanos, Cidadania e Violência/Ciência Política do Centro Universitário Unieuro

ISSN: $1809-1261$

UNIEURO, Brasília, número 23, Janeiro a Junho de 2018, pp. 178-210.

Nuevamente, con el comentario de Alan se presenta la disputa entre el ser y el deber ser: ...si nos damos cuenta cuáles son las funciones reales de cada parte puedes entender el sistema democrático como algo que personas ajenas a él hace que se maneje y se entienda mal, pero en sí, el sistema democrático no es un problema, sino el uso que hacemos de él y la simulación que permitimos que se haga con él.

Alfredo parece coincidir, si bien su percepción parece tener otros referentes: "Es que no estamos siendo gobernados por él, él es la imagen, pero detrás de él, hay un grupo empresarial que nos dirige desde una mesa ejecutiva junto con otros que están dirigiendo a donde va un país". No existe justicia, elemento que para Paola y Dafne es constitutivo de la democracia. La contradicción es manifiesta:

Retomando lo que han dicho todos mis compañeros, la democracia, viene a ser como el pueblo mediante un consenso elige a un representante y de manera coordinada se pretende llegar a un fin propio, pero pues como ellos también comentaban, esto responde a lo que la masa diga, a lo que los intereses que tengan todos en común, pues en la practicas, pues vemos que efectivamente no se lleva a cabo, ya por otras condiciones que todos ya bien conocemos, que la corrupción, que la dedocracia, que el compadrazgo, cosas que desde su origen siempre han existido y siempre han estado ahí latentes, y pues si se llevara a cabo como... se supone que teóricamente está planteada, puede funcionar y puede mejorar el bienestar de una sociedad y pues si esa se ve corrompida pues termina siendo un burdo circo. (Jorge)

\section{Perspectivas}

Por perspectivas entendemos en este trabajo el punto de vista que ofrecen las personas entrevistadas sobre la influencia de las llamadas reformas estructurales. Las participaciones motivadas para abordar sus efectos en la vida cotidiana y en el ámbito social, así como en razón de la prioridad que las personas les asignan. 
Artigo original

Hegemonia - Revista Eletrônica do Programa de Mestrado em Direitos Humanos, Cidadania e Violência/Ciência Política do Centro Universitário Unieuro

ISSN: $1809-1261$

UNIEURO, Brasília, número 23, Janeiro a Junho de 2018, pp. 178-210.

\subsection{Influencia de las reformas estructurales en la vida cotidiana}

Los efectos que identifican las personas son tanto benéficos como adversos, incluyendo cierta percepción de pérdida. Las variaciones muestran también el conocimiento relativo que cada una de ellas posee sobre las diversas reformas. En términos generales se hace mención de la laboral, la energética, la de telecomunicaciones, la hacendaria y de manera destacada por la importancia que le es atribuida la educativa. Aldo, por ejemplo, señala:

...yo solo conozco dos de las que ya están aprobadas, y que yo como ingeniero, bueno como cuasi ingeniero voy a poder aprovechar por el desarrollo tecnológico que aportará, tanto para mí como para la empresa a la que estoy sirviendo y más que nada para México....

La otra es la energética, no estoy muy relacionado con ella la verdad, solo sé que se permitió....Hablando del dinero, uno nunca va a saber si es o no es, si está controlado o diseñado o no para los mexicanos, uno sabe que ahí hay dinero y mucho dinero que está de por medio, nosotros sabemos que nuestros políticos hacen cualquier cosa por ser parte de ese dinero y a nosotros no nos va a tocar mucho realmente.

La sensación de pérdida se vincula con el ejercicio de la política y la ineficiencia, como lo plantea Edgar:

...pues iniciando con la reforma energética, yo lo que pienso es que México tiene suficiente capacidad, suficiente materia prima, como para llegar a ser una de las mejores naciones en cuanto al petróleo, nada más que la política lo ha debilitado demasiado, entonces lo que yo creo que al momento de privatizar el petróleo, como cabalmente se está diciendo, estamos perdiendo mucho.

Para Alondra esta situación sólo profundiza el estado de cosas vigente:

Yo creo que es algo que se ve reflejado mucho porque cada vez que hacen reformas, cada vez nos dejan más jodidos a todos y o sea, y de una manera como nos quieren privatizar muchas cosas si realmente se supone que hay una constitución que nos da los 
Artigo original

Hegemonia - Revista Eletrônica do Programa de Mestrado em Direitos Humanos, Cidadania e Violência/Ciência Política do Centro Universitário Unieuro

ISSN: $1809-1261$

UNIEURO, Brasília, número 23, Janeiro a Junho de 2018, pp. 178-210.

derechos no, y se supone que todo el suelo, el territorio mexicano que es de nosotros, y nos damos cuenta que realmente nos están robando, lo nuestro nos lo están quitando.

Para Jessica, que está en educación, "la reforma educativa no sirve para nada, ya no hay estímulo, porque pueden reprobar y no pasa nada, llegan a la prepa sin saber nada, y dicen: 'de todos modos voy a pasar ¿para qué me esfuerzo?”. Al respecto Edgar plantea: “yo creo que la educación no va a mejorar sólo por ponerles exámenes a los profesores para ver si son aptos o no son aptos." Su crítica es clara: "Sí se quería hacer en verdad un reforma educativa,... que influyera en verdad, se le debió haber dado más recursos, diferentes formas en que se podía ayudar la educación en México, en esa no estoy de acuerdo, la verdad.”

Dafne es crítica también y se centra en los docentes:

En esta está reforma es solamente un disfraz para la mediocridad en la educación en México, es una reforma que va enfocada en los maestros... Pero se enfoca en hacerlos menos, siendo que son la base que va a ayudar a nuestros niños que van a formar parte del futuro en su educación, siendo que es lo crucial para este país, que es lo que más falta y en lo que más fallamos.

Algunas personas identifican ventajas. Por ejemplo Jorge, indica: "En mi vida, la reforma que más afectaría sería la reforma de telecomunicaciones, me beneficia a mí directamente" y reconoce que la energética tiene un impacto general, en tanto la educativa lo será a largo plazo. Gregoria ilustra otra perspectiva: “estas reformas estructurales básicamente están retomando el espíritu neoliberal, es Estado mínimo, mayor participación de los entes privados, es lo que hace... con la reforma laboral se están flexibilizando las normas". Su reflexión apunta por una mayor presencia del estado: "a lo mejor no es momento para tener un Estado débil, tal vez deberíamos tener un Estado que regule más, que esté al pendiente de la vulnerabilidad.” Y sobre la vulnerabilidad se aprecia el juicio que sobre la reforma hacendaria hace Jorge:

También uno de los puntos flacos que tiene la reforma fiscal es el de intentar cambiar el sistema tributario e intentar hacerlo un poco más moderno, pero también las personas que diseñaron esta política, no se pusieron a revisar que lo que realmente predomina son 
Artigo original

Hegemonia - Revista Eletrônica do Programa de Mestrado em Direitos Humanos, Cidadania e Violência/Ciência Política do Centro Universitário Unieuro

ISSN: $1809-1261$

UNIEURO, Brasília, número 23, Janeiro a Junho de 2018, pp. 178-210.

microempresas que su estructura no da para actualizarse e insertarse en ese sistema, entonces yo creo que ahí si debieron haber prestado atención a ver cómo era el mecanismo que se adapta a la estructura productiva del país.

Las contrataciones bajo el esquema de subcontratación (outsourcing) en el ámbito laboral, la extracción de gas shale en el Valle de Juárez mediante el procedimiento de fracturación hidráulica (fracking) en torno a la reforma energética, y el incremento del impuesto al valor agregado (IVA) en la frontera norte al 16\%, como expresión de la reforma hacendaria, son retomadas y referidas por Aldo. Según Gregorio, "la reforma de telecomunicación, es también un favorecimiento hacía los poderes fácticos" y añade: “es lo que veo mayormente en estas reformas, una mayor participación de los poder facticos".

\subsection{Beneficios y/o perjuicios de las reformas estructurales en nuestro contexto social}

La elaboración de juicios sobre la influencia de las reformas pasó por el reconocimiento de que no se posee la información necesaria para realizar una estimación o valoración plena. Al respecto, Diego expresa:

Yo creo que hay que ser muy, tomar lo de las reformas con una, con una, con cierto escepticismo, creo que hay que ser muy puntual en todas las reformas, no podemos decir que todas son malas, que todas son muy buenas, hay que analizar puntualmente cada una de ellas.

¿Qué elementos destacaron las y los estudiantes? Aldo considera que tendrá efectos a largo plazo en el empleo y que pudiera mejorar la economía pero no la calidad de vida, pues no observa planteamientos de protección para los trabajadores. En el mismo sentido, Jessica ejemplifica el efecto de la reforma al IVA:

Por ejemplo en mi caso, que soy trilliza, me afecta la del I.V.A., porque los alimentos son bien caros y somos una familia de siete personas y solamente trabaja mi papá y sube la comida a cada rato entonces es muy costoso para nosotros estar comprando alimento 
Artigo original

Hegemonia - Revista Eletrônica do Programa de Mestrado em Direitos Humanos, Cidadania e Violência/Ciência Política do Centro Universitário Unieuro

ISSN: $1809-1261$

UNIEURO, Brasília, número 23, Janeiro a Junho de 2018, pp. 178-210.

porque gastamos más de seis mil pesos al mes en comprar lo que es comida para todos nosotros.

Para Abril, Natalia y Alondra los efectos más notorios se encuentran en el incremento de los precios y la dificultad de acceder a alimentos y otros bienes, pues observan que el incremento de los sueldos siempre va seguido de un incremento a los precios, lo que dificulta aún más la situación. Ethiel considera que los beneficios son pocos y para observarlos se requieren al menos de 10 años: "quién sabe cómo se encuentre la sociedad, la economía, la población, la política, por lo tanto si se produce algún tipo de beneficio, puede que este se diluya ante tanto aspecto diferente." En su perspectiva, la política y las reformas no necesariamente van en el mismo sentido: “dependiendo de la decisión de los políticos puede que estas reformas impacten de manera positiva, todo depende como lo sigan manejando."

David comparte este juicio:

...pienso que las reformas se han implementado para hacer un beneficio mutuo de la sociedad, no nada más de ciertos grupos de la sociedad y estos no se van a ver a corto plazo, sino a largo plazo y pues estas fallas del gobierno son las que hacen que todo este tipo de cambios en la política no funcionen de la manera correcto ni en la manera en la que fueron estipuladas.

Parece existir una coincidencia en que dada la imagen que se tiene del Estado, los gobiernos y los políticos, sólo podrán ser consideradas estas reformas positivas si logran ser exitosas. Jorge apunta:

...el Estado tiene cierto estigma de que es ineficiente, entonces... a menos de que los objetivos de estas políticas se cumplan, que en todo momento es el crecimiento económico y la tasa sostenida al 6\%..., la sociedad lo verá como un "no hicieron bien las cosas", "pinche gobierno,...."

Ángel piensa que "es posible generar expectativas positivas" y considera, al igual que otros participantes, que un riesgo se encuentra en la falta de continuidad a que nos tienen acostumbrados los gobiernos: 
Artigo original

Hegemonia - Revista Eletrônica do Programa de Mestrado em Direitos Humanos, Cidadania e Violência/Ciência Política do Centro Universitário Unieuro

ISSN: $1809-1261$

UNIEURO, Brasília, número 23, Janeiro a Junho de 2018, pp. 178-210.

...estas reformas no van a solucionar los problemas que tiene México, pero son un avance, y creo que los futuros gobiernos federales deberían seguir apoyando lo que ya se aprobó, lo que se iba hacer, y no cambiar otra vez el enfoque en cómo llegar a un progreso, porque también debe de ser sostenido, un sexenio no es suficiente, entonces también requiere de cierto seguimiento.

Con relación a los actores beneficiados, Edgar hace referencia a los empresarios: "no queda más que esperar el resultado a largo plazo, pero también hay que recalcar que estas reformas están dirigidas al fomento de los empresarios, que en base a que este sector privado, se genere un desarrollo en el país".

Tenemos que la desconfianza y la duda sobre la materialización de que las reformas en el tiempo ofrezcan beneficios y que éstos sean para todos, pues como expresa Jesús: "estamos hablando de un cambio estructural que se pretendió hacerlo así para ayudar al país, yo la verdad no veo algún beneficio para la sociedad de clase baja.... es meramente manipulación decir que va a funcionar o es a largo plazo”. Desde otra perspectiva, Alan apunta en el mismo sentido:

Evidentemente hay reformas que son mucho más preocupantes que otras por que engloban situaciones mucho más estructurales, como la economía o la energética o la financiera o incluso la electoral, la de telecomunicaciones que llevaba unos 5 años cocinándose entre que si entre que no; pero hay unas que parecen irrisorias, como esta que están contando de la tecnología, es como Gabriel Quadri que se preocupaba por el acceso a internet cuando el 70\% de México no sabe qué es lo que va a comer en 2 días.

\subsection{Qué reformas deben tener máxima prioridad}

Una posición generalizada se manifestó por dar una mayor atención, en búsqueda de mejores logros e incluso como garantía para el éxito de las otras reformas, en la reforma educativa, esa 
Artigo original

Hegemonia - Revista Eletrônica do Programa de Mestrado em Direitos Humanos, Cidadania e Violência/Ciência Política do Centro Universitário Unieuro

ISSN: $1809-1261$

UNIEURO, Brasília, número 23, Janeiro a Junho de 2018, pp. 178-210.

disposición gubernamental de carácter administrativo que dejó para mejor ocasión la revisión y adecuación de los contenidos, recursos, métodos y estrategias del quehacer educativo.

La formación de las nuevas generaciones y la participación informada de las y los jóvenes se consideran elementos centrales. Edgar señala, por ejemplo:

...yo creo que la que más debería influir y la que más se debería impulsar sería la educativa, de ahí es de donde se va a desencadenar todo, de la educación de los niños que están en este momento, de ahí se va a desarrollar todo lo que es el futuro de México más adelante.... entonces sí queremos empezar a copiar reformas, que es lo que estamos haciendo, la energética, la fiscal, todas son sacadas de otros países, entonces copien también lo que es bueno

Dafne comparte la perspectiva: "los niños son el futuro de nuestro México y si no les tomamos la suficiente importancia ahora, el cambio no se va a ver reflejado en veinte años". Jacobo reitera el acuerdo: "ciertamente vamos a coincidir todos en la misma,... puesto que en ella se van haciendo los cambios,... todas los futuros profesionistas, las futuras personas que van a sacar adelante lo que viene siendo el país”. Aldo destaca el corporativismo y la formación humanista: "ahí vendría siendo para mí la raíz del problema, en primer lugar por el sindicato que debería deslindarse del Estado..., y una reestructuración de la curricula,... están creando personas técnicas, cuadradas y no humanos.” Mónica la asocia con la necesidad de pensar en los otros:

...sí todo parte de la educación, y sí se hace a seres humanos más preparados para cualquier cosa, no simplemente para cosas técnicas..., para todo hasta para la vida, estaría todo mejor, eso también señalo lo de competencias, a mí en lo personal no me gusta para nada, porque estamos creando seres que solamente están pensando en competir pero se les quita humanidad, entonces ya no se preocupan por los demás.

Alejandra reafirma lo expresado: "Estoy de acuerdo con los compañeros, sería la base de todo esto que hemos estado analizando. Sí hubiera buena educación habría seres humanos más conscientes del entorno en que vivimos, más pensantes”. Alondra refiere la intervención de 


\section{Artigo original}

Hegemonia - Revista Eletrônica do Programa de Mestrado em Direitos Humanos, Cidadania e Violência/Ciência Política do Centro Universitário Unieuro

ISSN: $1809-1261$

UNIEURO, Brasília, número 23, Janeiro a Junho de 2018, pp. 178-210.

diversos actores, individuales y colectivos, establece como criterio centrarse en la persona, ya que así "cambiarían las cosas, si la educación cambiara, por lo tanto, la reforma educativa es la más importante". Para Iskra es la base de todo: "es la parte en la que empiezas como que a crear tus criterios y de ahí ya se explota todo.”

Gregorio acepta esta visión, más considera que existen otras reformas importantes: la de telecomunicaciones, “a medida que se están generando las nuevas tecnologías creo que ya encuentra la sociedad más medios para poder expresarse"; "la reforma política, es a través de la política que el ciudadano puede encontrar los instrumentos para encontrar una reestructuración del país”. Él mismo identifica un obstáculo:

...pero aquí en estas reformas yo no veo como se pueda manifestar aún mayor esa participación ciudadana, no veo la revocatoria de mandato, no la veo, para mí es crucial que se involucre está figura constitucional, ósea es hacer valer al ciudadano, que es el mayor articulador de la política. Esa para mí sería la más importante, el involucramiento del ciudadano para la transformación de las instituciones.

Ángel avizora en la educación el medio para superar este obstáculo:

...yo le daría prioridad a la educación , sería al primero en el que me enfocaría porqué creo que es necesario tener un mayor nivel de educación para romper con este círculo vicioso de corrupción, es decir tener un Estado de derecho y este Estado de derecho fuerte es el que nos va a permitir progresar en muchos aspectos y que nos van a llevar finalmente a un desarrollo que tiene una participación activa a través de los mismos agentes del desarrollo que [son] la población, las empresas, las instituciones y creo que la educación es la base de todo y el gasto público juega un papel determinante.

Las reformas, pareciera ser la perspectiva central, requieren de tiempo y su éxito depende en gran medida de la participación de una ciudadanía capaz y habilitada para beneficiarse de las mismas.

Al final de cuentas si todas las demás reformas funcionan correctamente y se llega a un desarrollo, para que éste se pueda capitalizar de buena forma, se requiere de una 
Artigo original

Hegemonia - Revista Eletrônica do Programa de Mestrado em Direitos Humanos, Cidadania e Violência/Ciência Política do Centro Universitário Unieuro

ISSN: $1809-1261$

UNIEURO, Brasília, número 23, Janeiro a Junho de 2018, pp. 178-210.

población que sea capaz de pasar de un nivel de vida a otro, y yo creo que para eso requieres de una población que esté preparada para nuevos tipos de empleos, nuevos tipos de gobierno,... para tener una mayor participación ciudadana y..., entonces, creo que todos estos pequeños puntos son posibles si hay una mejora en la educación y si la reforma educativa tiene una buena resolución, por lo tanto creo que esa debería de ser la más importante.

Una pregunta surge en la interacción. ¿Cuál es el objetivo de las reformas?, pues sólo así es factible preguntarse a su vez sobre su preponderancia. Jorge la plantea y ofrece una respuesta tentativa:

Antes de responder esa pregunta, yo creo que sería pertinente preguntarse ¿cuál es el objetivo de la reforma? para poder sopesar y dar la debida importancia a cada una de ellas de acuerdo a su objetivo. Si se piensa que el objetivo es el crecimiento económico como tal, habría que darle una mayor ponderación a la reforma energética, luego la reforma hacendaria, y luego la de telecomunicaciones principalmente. Pero si lo que se quiere fomentar [es] la democracia y ese tipo de cosas, podría estar la reforma política, pero como bien mencionaba Miguel si ya su objetivo es una reforma estructural desde la sociedad pues aquí a la que habría que darle una vital importancia tamaño sol, es a la reforma educativa.

Otras voces, en menor medida, atribuyeron una mayor importancia a las reformas energética, hacendaria y de telecomunicaciones. No obstante, pareciera ser que las posiciones que ocupan las y los estudiantes, sus expectativas para la satisfacción de las necesidades individuales y sociales se encuentran vinculadas a su espacio cotidiano de interacción: la institución educativa.

\section{Reflexiones finales}

El reconocimiento de que las reformas estructurales se encuentran vinculadas necesariamente al ámbito de la política y de lo político, establece la necesidad de cuestionarnos sobre las 
Artigo original

Hegemonia - Revista Eletrônica do Programa de Mestrado em Direitos Humanos, Cidadania e Violência/Ciência Política do Centro Universitário Unieuro

ISSN: $1809-1261$

UNIEURO, Brasília, número 23, Janeiro a Junho de 2018, pp. 178-210.

concepciones que sobre ciudadanía y democracia están vigentes entre la población, al tiempo que se indaga sobre la percepción que se tiene sobre el campo político. Las y los estudiantes que participaron en los grupos focales confirmaron lo que las diversas encuestas muestran: la política y el desempeño de las autoridades, para ellas y ellos, los políticos, es insuficiente para dar respuesta a las necesidades identificadas como sociales.

De hecho, ante el conocimiento relativo que se tiene del tipo y amplitud de las reformas denominadas estructurales, el cuestionamiento se sitúa en el ámbito de la sospecha y en la urgencia de que los cambios se materialicen ahora y no en el mediano o largo plazo. Para ellas y ellos, si bien identifican algunas ventajas o promesas, la reforma fundamental tiene que ver con el ser humano, es decir con el ciudadano: un ciudadano mejor formado e informado, comprometido con su comunidad, sociedad o país, es la única garantía de que las propuestas y su implementación resulten exitosas.

No se descalifica la democracia como forma de organización político administrativa, incluso se reconoce su vigencia formal, se cuestiona la preeminencia de los llamados poderes fácticos, el poder de los partidos políticos y la existencia de un conjunto de prácticas corruptas. Sin embargo, este malestar hacia lo político, más que impulsar un quiebre con las instituciones, busca propiciar mejoras y cambios con la participación ciudadana.

\section{Referencias}

Almond, Gabriel y Sidney Verba 1963, The Civic Culture. Political Attitudes and Democracy in Five Nations. Princeton: Princeton University Press.

Castoriadis, Cornelius 1997, "El Imaginario Social Instituyente”. Zona Erógena. 35. 1-9.

Centro de Estudios Sociales y de Opinión Pública (CESOP) 2014, Reformas estructurales encuesta nacional en viviendas. México. LXII Legislatura Cámara de Diputados.

Cisneros Espinosa, José 2014, Análisis contextual de la aprobación de las reformas estructurales en México y el manejo de la "comunicación política. Memoria Encuentro 
Artigo original

Hegemonia - Revista Eletrônica do Programa de Mestrado em Direitos Humanos, Cidadania e Violência/Ciência Política do Centro Universitário Unieuro

ISSN: $1809-1261$

UNIEURO, Brasília, número 23, Janeiro a Junho de 2018, pp. 178-210.

Nacional AMIC 2014. México. Universidad Autónoma de San Luis Potosí. http:/ /amic2014.uaslp.mx/g14/g14_01.pdf (Consultado el 10 abril 2015).

Dávalos, Pablo 2011, "Neoinstitucionalismo y reforma estructural". Revista Mensual de Economía, Sociedad y Cultura. http://rcci.net/globalizacion/2011/fg1117.htm (Consultado el 9 de abril)

Elías, Norbert 1999, Sociología fundamental. España: Gedisa.

Encuesta sobre Ciudadanía y Participación, (ECP 2014). México. El Colegio Mexiquense A.C.

Fanelli, José María 2012, Las reformas estructurales en América Latina y los paradigmas del desarrollo. En "Enrique V. Iglesias, Intuición y ética en la construcción de Futuro". Coords. Cecilia Alemany y Andrés López, Uruguay: Red MercoSur de Investigaciones Económicas.

García, Antonio 1982, Modelos operacionales de reforma agraria y desarrollo rural en América Latina. Costa Rica: IICA.

Informe País sobre la Calidad de la Ciudadanía en México (IPCCM) 2014. México. Instituto Federal Electoral/El Colegio de México.

Johansson Mondragón, Steven 2014, Los partidos políticos ante la reforma petrolera en México. Estudios $\quad$ políticos, 37-60. http://www.scielo.org.mx/scielo.php?script=sci_arttext\&pid=S0185-

16162014000100003\&lng=es\&tlng=es. (Consultado 10 de abril de 2015).

Martínez, M. Loreto, Silva, Carmen y Hernández, Ana C. 2010, ¿En qué ciudadanía creen los jóvenes? Creencias, aspiraciones de ciudadanía y aspiraciones para la participación sociopolítica. PSYKHE, Vol. 19, N², 25-37.

Martínez Miguélez, Miguel 2004, Los Grupos Focales de Discusión como Método de Investigación. En: http://miguelmartinezm.atspace.com/gruposfocales.html\#_ftn1 (Consultado 9 de febrero de 2015).

Martínez Ríos, Jorge 1965, La reforma agraria. Conflictos y consensos: el caso latinoamericano. Instituto de Investigaciones sociales. México: Universidad Autónoma de México. 
Artigo original

Hegemonia - Revista Eletrônica do Programa de Mestrado em Direitos Humanos, Cidadania e Violência/Ciência Política do Centro Universitário Unieuro

ISSN: $1809-1261$

UNIEURO, Brasília, número 23, Janeiro a Junho de 2018, pp. 178-210.

Moreno, Daniel y Antonio Araníbar 2012, El malestar ciudadano con la política. Marco conceptual y metodológico. En Crisis Global y Democracia en América Latina. Coords. Antonio Aranívar y Federico Vázquez. OEA/PNUD/Siglo XXI. Argentina.

Morgan, David L. 1996, Focus Groups. Annual Review of Sociology, Vol. 22, pp. 129-152. En: http://www.jstor.org/stable/2083427 (página consultada el 9 de febrero de 2015)

Morgan, David L. - Spanish, Margaret T. 1984, Focus Groups: A New Tool for Qualitative Research. Qualitative Sociology, 7 (3), September 1, pp. 253-270.

Olvera, Alberto 2008, Ciudadanía y Democracia. Cuadernos de Divulgación de la Cultura Democrática. Instituto Federal Electoral. México.

Quinta Encuesta Nacional de Cultura Política y Prácticas Ciudadanas (ENCUP), 2012. Secretaría de Gobernación. México. En http://www.encup.gob.mx/ (página consultada el 3 de abril de 2015)

Rubio, Luis; Oliver Azuara, Edna Jaime y César Hernández 2006, México 2025: el futuro se construye hoy, prólogo de Carlos Fernández González, México: CIDAC. http://cidac.org/esp/uploads/1/M_xico_2025._El_futuro_se_construye_hoy.pdf

(Consultado 10 abril de 2015)

Taylor, S. J. y Bogdan, R. 2008, Introducción a los métodos cualitativos de investigación. Barcelona: Paidós.

Trejo Ramírez, Marina y Agustín Andrade Robles 2013. "Evolución y desarrollo de las reformas estructurales en México (1982-2012)” El Cotidiano 177 (enero-febrero): 37-46

Zamitiz Gamboa, Héctor 2010, "Reformas estructurales, reforma del Estado y democratización en México (1982-2009)". Estudios políticos (20), 29-55. http://www.scielo.org.mx/scielo.php?script=sci_arttext\&pid=S0185-

16162010000200003\&lng=es\&tlng=es. (Consultado el 10 de abril de 2015)

\section{Anexos}

Guión del grupo focal. 
Hegemonia - Revista Eletrônica do Programa de Mestrado em Direitos Humanos, Cidadania e Violência/Ciência Política do Centro Universitário Unieuro

ISSN: $1809-1261$

UNIEURO, Brasília, número 23, Janeiro a Junho de 2018, pp. 178-210.

Preguntas generadoras

1. ¿Qué significa ser ciudadano o ciudadana? ( $\mathrm{Si}$ es grupo de un sexo, preguntar de acuerdo al mismo. En grupo mixto, considerar ambas formulaciones).

2. Cuándo escuchan la palabra política, ¿con cuáles palabras la relacionan?

3. ¿Qué sienten cuando escuchan la palabra democracia?

4. ¿Cuáles son algunas de las formas en que su vida cotidiana se verá influida por las reformas estructurales recientemente aprobadas?

5. ¿Qué piensan acerca de los beneficios y/o perjuicios que pueden generar las reformas estructurales en nuestro contexto social?

6. ¿Qué reformas piensan que deben tener máxima prioridad? 